\title{
SNW1 is a prognostic biomarker in prostate cancer
}

\author{
Doris Höflmayer ${ }^{1 \dagger}$, Carla Willich ${ }^{1 \dagger}$, Claudia Hube-Magg ${ }^{1}$, Ronald Simon ${ }^{1 *}$ (D, Dagmar Lang ${ }^{1}$, Emily Neubauer ${ }^{1}$, \\ Frank Jacobsen ${ }^{1}$, Andrea Hinsch', Andreas M. Luebke', Marie Christina Tsourlakis', Hartwig Huland², \\ Markus Graefen², Alexander Haese², Hans Heinzer², Sarah Minner', Franziska Büscheck', Guido Sauter', \\ Thorsten Schlomm ${ }^{3}$, Stefan Steurer ${ }^{1}$, Till S. Clauditz ${ }^{1}$, Eike Burandt ${ }^{1}$, Waldemar Wilczak ${ }^{1}$ and Christian Bernreuther ${ }^{1}$
}

\begin{abstract}
Background: SNW1 is a nuclear receptor co-activator involved in splicing and transcription control, including androgen receptor signaling. Overexpression of SNW1 has been linked to adverse prognosis in different cancer types, but studies on the role of SNW1 in prostate cancer are lacking.

Methods: Using immunohistochemistry, we analyzed SNW1 expression in 10,310 prostate cancers in a tissue microarray (TMA) with attached clinical and molecular data.

Results: The comparison with normal prostate tissue revealed an up regulation of SNW1 in a subset of cancer samples. SNW1 staining was considered weak in $31.5 \%$, moderate in $37.7 \%$ and strong in $14 \%$ of cancers. Strong SNW1 expression was markedly more frequent in prostate cancers harboring the TMPRSS2:ERG fusion (24\%) than in ERG negative cancers $(7 \%, p<0.0001)$. Significant associations with Gleason grade, stage, nodal status and early biochemical recurrence were observed in the ERG negative and positive subset. Multivariable modeling revealed that the prognostic value of SNW1 up regulation was independent from the established preoperative histopathological and clinical parameters.
\end{abstract}

Conclusion: These results demonstrate that SNW1 overexpression is an independent prognostic marker in prostate cancer with potential clinical utility.

Keywords: SNW1, Prostate cancer, Prognosis, TMPRSS2:ERG, SKIP1

\section{Background}

Prostate cancer was estimated to be the most frequent diagnosed cancer and the third most common cause of cancer related death in men with western lifestyle in 2012 [1]. About 1 in 5 patients diagnosed with prostate cancer probably dies due to the cancer in developed countries. Established pretreatment prognostic parameters include Gleason grade and tumor extent on biopsies, preoperative prostate-specific antigen (PSA) levels, and clinical stage. Unfortunately, a reliable distinction between indolent and aggressive prostate cancer is still not possible in individual patients. It is hoped that

\footnotetext{
* Correspondence: r.simon@uke.de

${ }^{\dagger}$ Doris Höflmayer and Carla Willich contributed equally to this work. ${ }^{1}$ Institute of Pathology, University Medical Center Hamburg-Eppendorf, Martinistrasse 52, D-20246 Hamburg, Germany

Full list of author information is available at the end of the article
}

upcoming molecular markers may enable a better prediction of prostate cancer aggressiveness.

SNW domain-containing protein 1 (SNW1) alias SKI-interacting protein 1 (SKIP1) is a multifunctional protein implicated in the regulation of several genes and pathways connected to cell growth and homeostasis. It acts either by direct protein interactions, by mRNA splicing regulation, or by transcriptional control. SNW1 has been originally named after its direct interaction with the SKI oncogene in the regulation TGF- $\beta$ signaling $[2,3]$, but it also associates with the retinoblastoma tumor suppressor protein to impair its function [4], and stabilizes beta-catenin to enhance WNT-signaling [5]. In its function as a selective splicing factor for $\mathrm{p} 21$, SNW1 is known to counteract p53-mediated apoptosis [6]. Finally, SNW1 is an important co-regulator for nuclear receptors [7] including vitamin $\mathrm{D}$ receptor [8], progesterone and

(C) The Author(s). 2019 Open Access This article is distributed under the terms of the Creative Commons Attribution 4.0 International License (http://creativecommons.org/licenses/by/4.0/), which permits unrestricted use, distribution, and 
androgen receptor [9]. Given these numerous interactions with pathways relevant in cancer, it is not surprising that SNW1 can be up regulated in many cancer types. For example, overexpression of SNW1 was reported in 43\% of breast cancers [10], 50\% of liver cancers [11], 30\% of bladder cancers [12] and $40 \%$ of malignant pleural mesothelioma [13]. High SNW1 expression was associated with high tumor grade and proliferation in breast cancer [10] and with poor prognosis in the other above-mentioned tumor types [11-13]. Given its functional association with the androgen receptor, it appears possible that SNW1 expression may also be relevant in prostate cancer biology. Studies investigating the potential prognostic impact of SNW1 in clinical prostate cancer samples are currently missing.

To test the potential of SNW1 as a clinical marker in prostate cancer, the validated antibody HPA002457 from the Human Tissue Atlas Project [14] was employed for an immunohistochemical analysis of a highly annotated tissue micro array (TMA) with more than 12,000 prostate cancers.

\section{Methods}

\section{Patients}

The 12,427 patients had radical prostatectomy between 1992 and 2012 at the University Medical Center Hamburg-Eppendorf (Department of Urology and the Prostate Cancer Center Martini Clinic). Follow-up data were available for a total of 11,665 patients with a median follow-up of 60 months (range: 1 to 275 months; Table 1). PSA recurrence was defined as the time point at which postoperative serum PSA level was at least 0.2 $\mathrm{ng} / \mathrm{ml}$ and increasing. Prostate specimens were analyzed according to a standard procedure [15]. In addition to the classical Gleason categories, "quantitative" Gleason grading was performed as detailed in Sauter et al. [16]. The TMA manufacturing process was described before [17]. The highly annotated database of this TMA contained results on ERG expression [18], ERG break-apart FISH analysis [19] and androgen receptor (AR) expression [20].

\section{Immunohistochemistry (IHC)}

Freshly cut TMA sections were stained within one day in one assay. Slides were deparaffinized, rehydrated, washed in DAKO buffer (K8002) and transferred to a DAKO Link 48 autostainer. The polyclonal rabbit anti-SNW1 antibody HPA002457 supported by the Human Protein Atlas [14] was used at 1:150 dilution (HPA002457 Sigma, Merck, Darmstadt, Germany). The SNW1 staining was nuclear and paralleled by cytoplasmic co-staining of comparable intensity. The nuclear staining intensity $(0,1+, 2+$, and $3+)$ and the fraction of positive tumor cells were separately recorded for each
Table 1 Pathological and clinical data of the arrayed prostate cancers

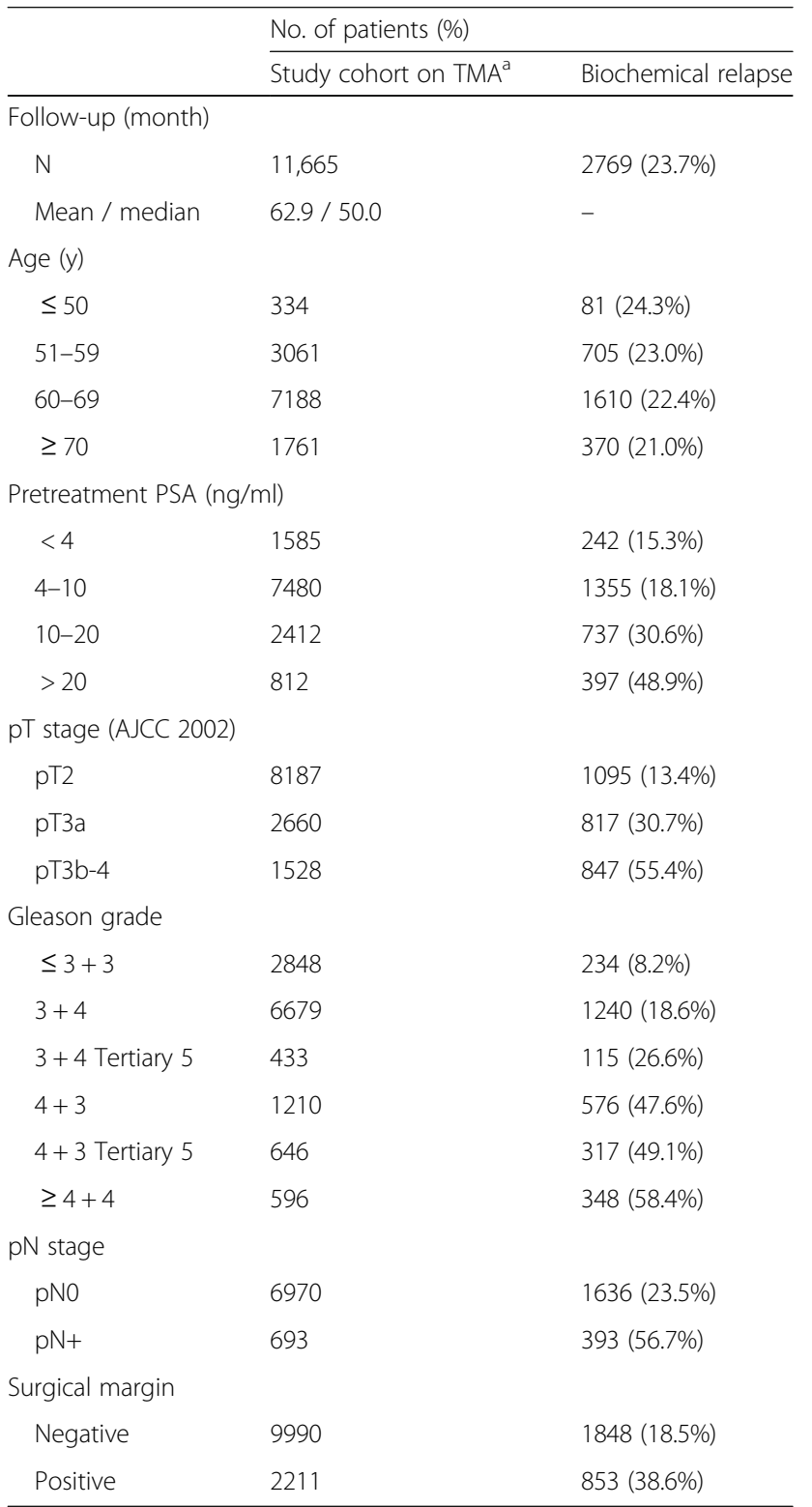

${ }^{a}$ Numbers do not always add up to 12,427 in different categories because of cases with missing data. Abbreviation: AJCC American Joint Committee on Cancer

tissue spot. A final score was built of these two parameters according to the following score, which has been previously described [19]: Negative scores had a complete absence of nuclear and cytoplasmic staining; weak scores had a nuclear staining intensity of $1+$ in $\leq 70 \%$ of the tumor cells or a staining intensity of $2+$ in $\leq 30 \%$ of the tumor cells; moderate scores had a nuclear staining intensity of $1+$ in $>70 \%$ of tumor cells, a staining intensity of $2+$ in $>30 \%$ but in $\leq 70 \%$ of the tumor cells or a staining intensity of $3+$ in $\leq 30 \%$ of the tumor cells; and strong scores had a nuclear staining intensity 
of $2+$ in $>70 \%$ of the tumor cells or a staining intensity of $3+$ in $>30 \%$ of the tumor cells. Scoring was done by two experienced pathologists with the help of a third one in cases with discordant results.

\section{Statistical analysis}

Contingency tables and the $x^{2}$-test were performed to search for associations between molecular parameters and tumor phenotype. Analysis of variance was applied to search for differences of the KI67 labeling index (Ki67LI). Kaplan-Meier survival curves were compared by the log-rank test. Cox proportional hazards regression analysis was performed to test for independence and significance between pathological, molecular and clinical variables. Significant factors of the univariate models were covariates in the multivariate model. Calculations were performed with JMP 10 (SAS Institute Inc., NC, USA).

\section{Results}

A total of $10,310(83 \%)$ tumor samples were interpretable in our TMA analysis. Non-informative cases (2117; 17\%) lacked tissue samples or unequivocal cancer cells in the TMA spot (Additional file 1: Table S1). Normal prostate glands showed variable levels of cytoplasmic and nuclear SNW1 staining, ranging between negative and moderate intensity (Additional file 1: Figure S1). In prostate cancers, positive SNW1 staining was found in $83.1 \%$ of cases, and was considered weak in $31.5 \%$, moderate in $37.7 \%$ and strong in $14 \%$ of cases. Representative images are shown in Fig. 1.

\section{Association with TMPRSS2:ERG fusion status and ERG protein expression}

To evaluate whether SNW1 expression is associated with ERG status in prostate cancers, we used data from previous studies (expanded from $[18,19]$ ). Data on both ERG FISH and IHC were available from 6778 cancer samples and an identical result (ERG IHC positive and break by FISH or ERG IHC negative and missing break by FISH) was found in more than $95 \%$ of the examined cancer samples. SNW1 expression was strongly linked to TMPRSS2:ERG rearrangement and ERG expression in our set of prostate cancers. For example, moderate to strong SNW1 staining was seen in $37.9 \%$ of ERG-IHC negative but in $71.4 \%$ of ERG-IHC positive cancers $(p<$ 0.0001). This was particularly evident for cancer samples with strong SNW1 expression, which was found in only $7 \%$ of ERG negative but in $24 \%$ of ERG positive cancers. All data are summarized in Fig. 2.
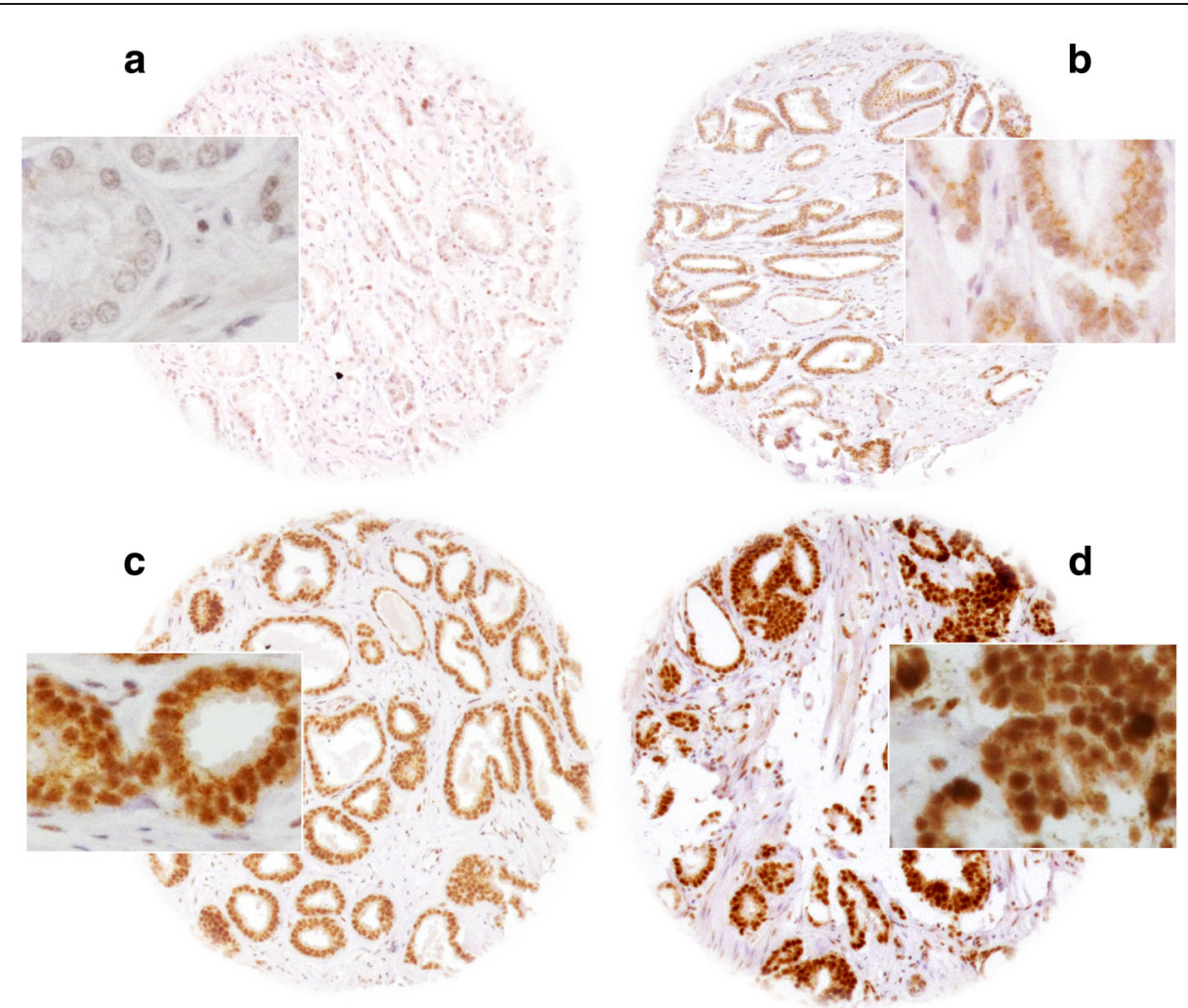

Fig. 1 Representative pictures of a) negative, b) weak, c) moderate and d) strong SNW1 staining in prostate cancer. Spot size is $600 \mu m$ at $100 x$ and 400x (inset) magnification 


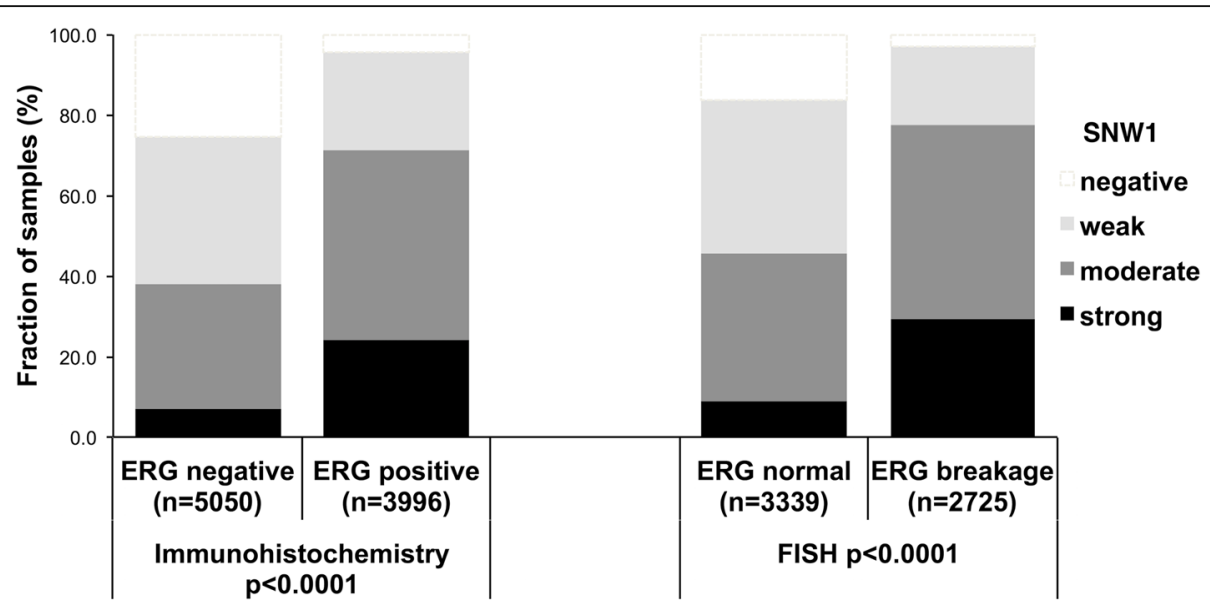

Fig. 2 Association between positive SNW1 staining and ERG-status (Immunohistochemistry / FISH) in all cancers

\section{Associations with tumor phenotype}

Elevated SNW1 staining was linked to advanced tumor stage $(<0.0001)$, high classical or quantitative Gleason grade $(<0.0001$ each), nodal metastasis $(<0.0001)$, and positive surgical margin $(p=0.0034)$ if all tumors were jointly analyzed (Table 2). Subset analysis of ERG fusion negative and positive cancers showed these associations in both subsets (Additional file 1: Table S2).

\section{Association with tumor cell proliferation}

High-level SNW1 staining was significantly linked to high cell proliferation as measured by Ki67LI. The

Table 2 Association between SNW1 staining and prostate cancer phenotype

\begin{tabular}{|c|c|c|c|c|c|c|}
\hline \multirow[b]{2}{*}{ Parameter } & \multirow[b]{2}{*}{$\mathrm{N}$} & \multicolumn{5}{|l|}{ SNW1 (\%) } \\
\hline & & Negative & Weak & Moderate & Strong & $P$ \\
\hline All cancers & 10,310 & 16.9 & 31.5 & 37.7 & 14.0 & \\
\hline Tumor stage & & & & & & $<0.0001$ \\
\hline pT2 & 6668 & 18.7 & 33.2 & 36.3 & 11.8 & \\
\hline рT3a & 2289 & 15.0 & 27.0 & 40.3 & 17.6 & \\
\hline pT3b-pT4 & 1313 & 10.2 & 30.2 & 40.1 & 19.5 & \\
\hline Gleason grade & & & & & & $<0.0001$ \\
\hline$\leq 3+3$ & 2302 & 25.0 & 34.2 & 31.9 & 8.9 & \\
\hline $3+4$ & 5275 & 16.1 & 31.2 & 38.0 & 14.7 & \\
\hline $3+4$ Tertiary 5 & 382 & 13.6 & 31.2 & 43.5 & 11.8 & \\
\hline $4+3$ & 916 & 12.2 & 27.9 & 41.2 & 18.7 & \\
\hline $4+3$ Tertiary 5 & 564 & 9.8 & 25.2 & 41.8 & 23.2 & \\
\hline$\geq 4+4$ & 420 & 7.9 & 28.1 & 46.2 & 17.9 & \\
\hline Lymph node metastasis & & & & & & $<0.0001$ \\
\hline No & 5818 & 16.0 & 30.4 & 38.5 & 15.1 & \\
\hline $\mathrm{N}+$ & 591 & 8.3 & 27.6 & 45.2 & 19.0 & \\
\hline Preoperative PSA level (ng/ml) & & & & & & 0.0011 \\
\hline$<4$ & 1278 & 13.2 & 30.0 & 41.6 & 15.2 & \\
\hline $4-10$ & 6160 & 16.8 & 31.4 & 37.4 & 14.4 & \\
\hline $10-20$ & 2047 & 18.1 & 32.6 & 36.3 & 13.0 & \\
\hline$>20$ & 713 & 19.1 & 31.0 & 37.4 & 12.5 & \\
\hline Surgical margin & & & & & & 0.0034 \\
\hline Negative & 8178 & 17.4 & 31.7 & 37.5 & 13.5 & \\
\hline Positive & 1947 & 14.8 & 30.8 & 38.4 & 16.0 & \\
\hline
\end{tabular}


average Ki67LI increased from $1.33 \pm 0.08$ in cancers lacking SNW1 expression to $2.55 \pm 0.06$ (weak), $3.25 \pm$ 0.05 (moderate) and to $3.8 \pm 0.09$ in cancers with strong SNW1 expression $(p<0.0001)$. This association held true in all tumor subsets with identical Gleason score $(\leq 3+3: p<0.001,3+4: p<0.0001,4+3: p<0.0001, \geq 4$ $+4: p=0.0060$; data not shown). This relationship was more prominent in ERG negative than in ERG positive cancers (Additional file 1: Tables S3 and S4).

\section{Association with androgen receptor}

Because SNW1 is a known co-factor of androgen receptor signaling [9], we compared SNW1 expression with immunohistochemistry data on AR expression from a previous study [20]. Immunohistochemistry data on both SNW1 and AR were available from 6984 cancers. There was a strong and linear increase of SNW1 with increasing AR expression: Only $2 \%$ of AR-negative, but $25 \%$ of cancers with strong AR expression showed strong SNW1 expression $(p<0.0001$; Fig. 3$)$.

\section{Association with PSA recurrence}

Follow-up data were available for 9284 patients with interpretable SNW1 staining on the TMA. High-level SNW1 expression was associated with early PSA recurrence $(p<0.0001$, Fig. 4a). Subgroup analyses of ERG negative $(p<0.0001$, Fig. $4 \mathrm{~b})$ and ERG positive cancers ( $p=0.0002$, Fig. $4 \mathrm{c})$ revealed that the prognostic impact of SNW1 was significant in both subsets. To estimate the impact of the Gleason grade on the prognostic power of SNW1, we performed further subset analyses in ERG negative cancers with identical classical and quantitative Gleason grade. Here, SNW1 staining did not provide significant prognostic information beyond the classical or quantitative Gleason grade (Additional file 1: Figure S2).
Uni- and multivariable analysis

Table 3 shows the hazard ratios for the established preoperative risk factors Gleason grade obtained on the original biopsy, preoperative PSA level, and cT stage together with the SNW1 expression ranked by their decreasing Cox proportional hazard in the uni- and multivariable model. SNW1 expression had a moderate effect in both models. The effect was seen in the ERG negative and ERG positive subset, although it was weaker in the later.

\section{Discussion}

The results of our study demonstrate that SNW1 overexpression is linked to aggressive tumor features and poor prognosis in prostate cancers. Our immunohistochemical analysis revealed at least weak SNW1 staining in $83 \%$ of our 10,310 interpretable prostate cancers. Normal prostate glands showed variable levels of SNW1 expression, ranging from negative to moderate staining in our study. That a strong SNW1 immunostaining - at a level not observed in normal prostate epithelium - was found in $14 \%$ of prostate cancers suggests that SNW1 becomes up regulated during tumor development in a fraction of prostate cancers. Comparable data derived from immunohistochemical analyses of SNW1 in prostate cancer are currently lacking in the literature. Data from RNA sequencing of prostate cancers do not show major SNW1 mRNA expression changes [21], suggesting that stabilization may account for the increased levels identified by immunohistochemistry. However, data supporting SNW1 up regulation in malignant tumors comes from breast cancer [10], hepatocellular carcinoma [11], bladder cancer [12] and malignant pleural mesothelioma [13].

Highly significant statistical associations of SNW1 overexpression with unfavorable tumor phenotype, accelerated cell proliferation and poor clinical outcome in our cohort of more than 10,000 patients identifies SNW overexpression as a sign for increased cancer aggressiveness. These observations fit well to the role of SNW1 as

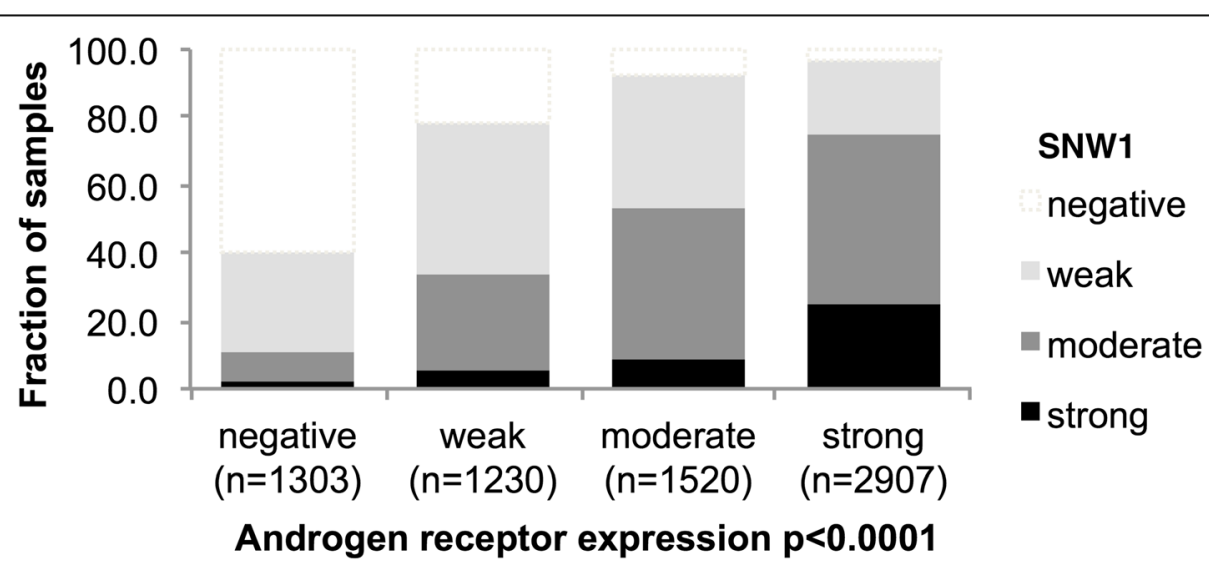

Fig. 3 Association between SNW1 and androgen receptor expression 


\section{a All cancers}

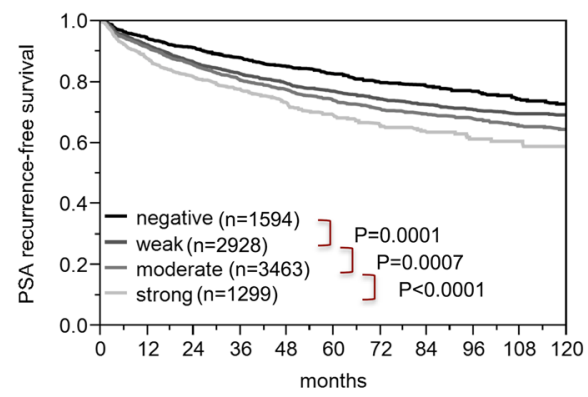

\section{b ERG-negative subset}

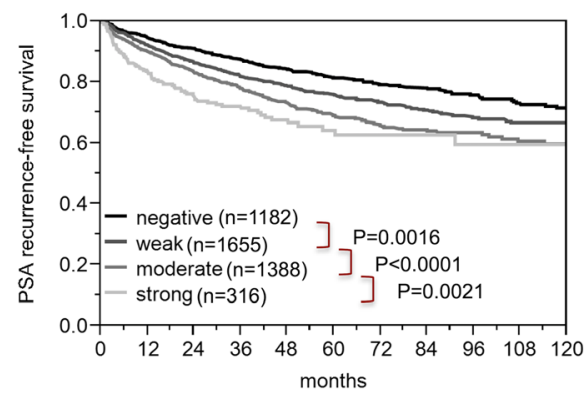

C ERG-positive subset

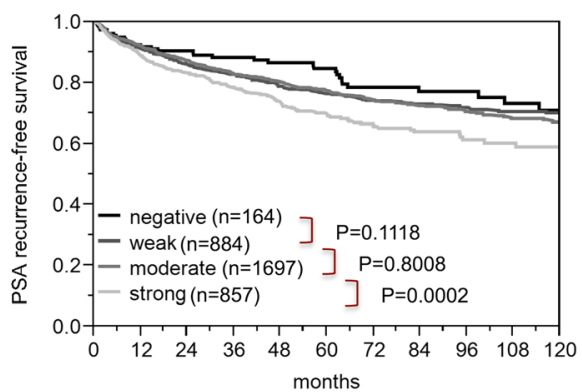

Fig. 4 Association between SNW1 expression and biochemical recurrence in a) all cancers, b) the ERG-fusion negative, and c) ERG-fusion positive subsets

co-activator of known oncogenic pathways [2, 3], such as transforming growth factor $\beta$ (TGF- $\beta$ ) [2] and WNT signaling [5]. Functional studies have further demonstrated, that SNW1 counteracts p53-mediated apoptosis [6] and inhibits the transcriptional repressor activity of the retinoblastoma tumor suppressor gene [4]. Accordingly, associations of SNW1 up regulation with unfavorable tumor features have also been reported from several other malignancies. For example, SNW1 overexpression

Table 3 Cox proportional hazards for PSA recurrence-free survival after prostatectomy of established preoperative prognostic parameter and SNW1 expression

\begin{tabular}{|c|c|c|}
\hline Variable & Univariable analysis & Multivariable analysis \\
\hline \multicolumn{3}{|l|}{ Gleason grade biopsy } \\
\hline$\geq 4+4$ vs. $\leq 3+3$ & $6.01(5.41-6.66) * * *$ & $4.05(3.58-4.58) * * *$ \\
\hline \multicolumn{3}{|c|}{ Preoperative PSA-level (ng/ul) } \\
\hline$>20$ vs. $<4$ & $5.12(4.46-5.89) * * *$ & $3.61(3.00-4.35) * * *$ \\
\hline \multicolumn{3}{|l|}{ cT-stage } \\
\hline T2b vs. T1c & $2.16(1.73-2.66) * * *$ & $1.84(1.62-2.08) * * *$ \\
\hline \multicolumn{3}{|l|}{ SNW1 expression } \\
\hline Strong vs. negative & $1.95(1.69-1.26) * * *$ & $1.63(1.40-1.89) * * *$ \\
\hline ERG negative subset & $2.38(1.90-2.97) * * *$ & $1.88(1.49-2.35) * * *$ \\
\hline ERG positive subset & $1.81(1.30-2.60) * *$ & $1.48(1.06-2.14) *$ \\
\hline
\end{tabular}

The multivariable model included all the four-univariate factors. Confidence interval (95\%) in brackets; asterisk indicate significance level: ${ }^{*} p \leq 0.05,{ }^{* *} p \leq 0.001$, ${ }^{* * *} p \leq 0.0001$; ERG ETS-related gene is linked to high tumor grade and accelerated cell proliferation in breast cancer [10], and to poor prognosis in urinary bladder cancer, hepatocellular carcinoma, and malignant pleural mesothelioma [11-13].

The availability of a molecular database attached to this prostate cancer TMA enabled us to investigate the role of SNW1 in molecularly defined cancer subgroups, the most relevant of which are ERG positive and ERG negative cancers. TMPRSS2:ERG fusions occur in about $50 \%$ of prostate cancers [22]. They predominantly occur in younger patients [18] and lead to a constitutive overexpression of the transcription factor ERG [22]. ERG overexpression by itself lacks any prognostic impact, at least in patients not receiving systemic therapy. However, ERG modulates the expression of more than 1600 genes in prostate epithelial cells ERG [23-25]. The biological effects of various proteins may be mitigated or intensified in such a modified cellular microenvironment. Our data identify SNW1 expression as an ERG-dependent feature being clearly more prominent in ERG positive than in ERG negative cancers. It appears possible, that SNW1 up regulation in ERG-fusion positive tumors is mediated by ERG-dependent activation of TGF- $\beta$ signaling. Earlier studies have shown that TGF- $\beta$ signaling is massively up regulated in ERG-positive cancers [24], and that TGF- $\$ 1$ increases SNW1 expression in mouse models [26]. The strong association between SNW1 overexpression and increased AR expression 
observed in our study fits well to earlier reports on a functional relationship between these proteins. For example, Abwanka et al. [9] demonstrated that binding of testosterone to the AR and nuclear translocation of activated AR is massively increased when SNW1 forms complexes with the AR.

The prognostic effect of SNW1 expression was stronger in ERG negative than in ERG positive cancers but also retained in the latter group. A modified cellular microenvironment may serve as an explanation for the particularly strong prognostic role of SNW1 expression in ERG negative cancers. In earlier studies we had described several molecular features that were either prognostic in ERG positive (for example, SOX9, [27] and SENP1 [28] or in ERG negative cancers (for example, GGH [29] and NBS1 [30]) but not in both groups. An alternative explanation for different prognostic effects between ERG positive and ERG negative cancers is the experimental set-up. It cannot be excluded that our immunohistochemistry protocol was better suited to distinguish expression differences in cancers with generally lower expression levels (ERG negative cancers) than in those with higher expression (ERG positive cancers). For example, the group of SNW1 negative cancers - the best prognostic group - contained 1182 cancers in ERG negative, but only 164 cancers in ERG positive cancers. Irrespective of its cause, the different prognostic impact of SNW1 in ERG positive and ERG negative cancers demonstrates that the applicability (and perhaps thresholds) of prognostic markers may depend on individual tumor features. This clearly represents a challenge for the development of prognostic cancer tests that shall be applicable to every patient.

The data of this study suggest that SNW1 expression may represent a clinically useful marker. It is of note that the search for clinically useful prognostic markers is not predominantly about finding factors that are independent of established parameters. Most of all, parameters are needed that are more reproducible and, thus, reliable in individual patients. The established prognostic factors (Gleason grade, preoperative PSA-level, clinical stage, pathological stage and nodal status) are statistically strong but suffer from significant shortcomings in clinical practice. pT stage and nodal status are not available during the preoperative therapeutic decision-making process. The quality of pN data greatly depends on the extent of surgery and the pathological work-up of the removed materials. The Gleason Grade - i.e., the most powerful preoperatively available prognostic marker - suffers from very substantial inter-observer variability reaching beyond $40 \%$ in individual biopsies [31]. SNW1 expression measurement thus clearly has potential to become an element in a future multi-parametric prognostic test for prostate cancer. To this end some of the limitations in the present study (retrospective analysis of a single spot per patient from prostatectomy specimen) have to be addressed.

\section{Conclusions}

SNW1 overexpression occurred in a relevant fraction of prostate cancers. The moderate prognostic impact of SNW1 makes it a candidate for future marker panels in prostate cancer.

\section{Additional file}

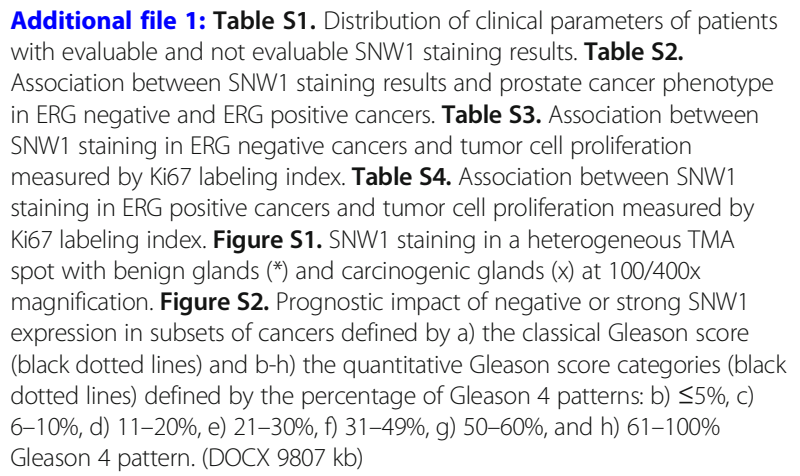

\section{Abbreviations \\ AR: Androgen receptor; ERG : Erythroblast transformation-specific (ETS) re- lated gene; FISH : Fluorescence in situ hybridization; \\ IHC: Immunohistochemistry; Ki67LI : Ki67 labeling index; PSA : Prostate specific antigen; SNW1: SNW domain-containing protein 1; TGF- \\ $\beta$ : Transforming growth factor $\beta$; TMA : Tissue microarray; TMPRSS2 : Trans membrane protease, serine $2 ; \mathrm{WNT}$ : Wingless Int-1}

\section{Acknowledgements}

The authors appreciate the excellent technical support of Christina Koop, Janett Lütgens, Sünje Seekamp, and Inge Brandt.

\section{Funding}

This work was supported by the Federal Ministry of Education and Research (BMBF) grant number 01KU1505B.

\section{Availability of data and materials}

All data generated or analyzed during this study are included in this published article [and its Additional file 1].

\section{Authors' contributions}

$\mathrm{DH}, \mathrm{CB}, \mathrm{RS}$, and GS designed the study, and drafted the manuscript. $\mathrm{HHu}$ $M G, A H a$ and TS participated in study design. CW, EN, FJ, AH, AML performed $I H C$ analysis and scoring. MCT and SM participated in pathology data analysis. $\mathrm{CH}$ and DL performed statistical analysis. FB, SS, TSC, EB, HHe and WW participated in data interpretation, and helped to draft the manuscript. All authors read and approved the final manuscript.

\section{Ethics approval and consent to participate}

The ethics committee of the Ärztekammer Hamburg approved this study (WF-049/09). According to local laws (HmbKHG, §12a) informed consent was not required for this study.

Consent for publication

Not applicable.

Competing interests

The authors declare that they have no competing interests. 


\section{Publisher's Note}

Springer Nature remains neutral with regard to jurisdictional claims in published maps and institutional affiliations.

\section{Author details}

'Institute of Pathology, University Medical Center Hamburg-Eppendorf, Martinistrasse 52, D-20246 Hamburg, Germany. ${ }^{2}$ Martini-Clinic, Prostate Cancer Center, University Medical Center Hamburg-Eppendorf, Martinistrasse 52, D-20246 Hamburg, Germany. ${ }^{3}$ Department of Urology, Charité Universitätsmedizin Berlin, Charitéplatz 1, D-10117 Berlin, Germany.

\section{Received: 7 December 2018 Accepted: 11 April 2019}

\section{Published online: 01 May 2019}

\section{References}

1. Torre LA, Bray F, Siegel RL, Ferlay J, Lortet-Tieulent J, Jemal A. Global cancer statistics, 2012. CA Cancer J Clin. 2015;65(2):87-108.

2. Leong GM, Subramaniam N, Figueroa J, Flanagan JL, Hayman MJ, Eisman $J A$, Kouzmenko AP. Ski-interacting protein interacts with Smad proteins to augment transforming growth factor-beta-dependent transcription. J Biol Chem. 2001;276(21):18243-8.

3. Xu W, Angelis K, Danielpour D, Haddad MM, Bischof O, Campisi J, Stavnezer E, Medrano EE. Ski acts as a co-repressor with Smad2 and Smad3 to regulate the response to type beta transforming growth factor. Proc Natl Acad Sci U S A. 2000;97(11):5924-9.

4. Prathapam T, Kuhne C, Banks L. Skip interacts with the retinoblastoma tumor suppressor and inhibits its transcriptional repression activity. Nucleic Acids Res. 2002:30(23):5261-8.

5. Wang Y, Fu Y, Gao L, Zhu G, Liang J, Gao C, Huang B, Fenger U, Niehrs C, Chen YG, et al. Xenopus skip modulates Wnt/beta-catenin signaling and functions in neural crest induction. J Biol Chem. 2010;285(14):10890-901.

6. Chen Y, Zhang L, Jones KA. SKIP counteracts p53-mediated apoptosis via selective regulation of p21Cip1 mRNA splicing. Genes Dev. 2011;25(7):701-16.

7. Leong GM, Subramaniam N, Issa LL, Barry JB, Kino T, Driggers PH, Hayman MJ, Eisman JA, Gardiner EM. Ski-interacting protein, a bifunctional nuclear receptor coregulator that interacts with N-CoR/SMRT and p300. Biochem Biophys Res Commun. 2004:315(4):1070-6.

8. Baudino TA, Kraichely DM, Jefcoat SC Jr, Winchester SK, Partridge NC, MacDonald PN. Isolation and characterization of a novel coactivator protein, NCoA-62, involved in vitamin D-mediated transcription. J Biol Chem. 1998; 273(26):16434-41.

9. Abankwa D, Millard SM, Martel N, Choong CS, Yang M, Butler LM, Buchanan G, Tilley WD, Ueki N, Hayman MJ, et al. Ski-interacting protein (SKIP) interacts with androgen receptor in the nucleus and modulates androgendependent transcription. BMC Biochem. 2013;14:10.

10. Liu X, Ni Q, Xu J, Sheng C, Wang Q, Chen J, Yang S, Wang H. Expression and prognostic role of SKIP in human breast carcinoma. J Mol Histol. 2014; 45(2):169-80.

11. Liu G, Huang X, Cui X, Zhang J, Wei L, Ni R, Lu C. High SKIP expression is correlated with poor prognosis and cell proliferation of hepatocellular carcinoma. Med Oncol. 2013;30(3):537.

12. Wang L, Zhang M, Wu Y, Cheng C, Huang Y, Shi Z, Huang H. SKIP expression is correlated with clinical prognosis in patients with bladder cancer. Int J Clin Exp Pathol. 2014;7(4):1695-701.

13. Turkcu G, Alaballk U, Keles AN, Ibiloglu I, Kucukoner M, Sen HS, Buyukbayram H. Comparison of SKIP expression in malignant pleural mesotheliomas with Ki-67 proliferation index and prognostic parameters. Pol J Pathol. 2016;67(2):108-13.

14. Uhlen $M$, Oksvold $P$, Fagerberg L, Lundberg E, Jonasson K, Forsberg M, Zwahlen M, Kampf C, Wester K, Hober S, et al. Towards a knowledge-based human protein atlas. Nat Biotechnol. 2010;28(12):1248-50.

15. Erbersdobler A, Fritz H, Schnoger S, Graefen M, Hammerer P, Huland H, Henke RP. Tumour grade, proliferation, apoptosis, microvessel density, p53, and bcl-2 in prostate cancers: differences between tumours located in the transition zone and in the peripheral zone. Eur Urol. 2002;41(1):40-6.

16. Sauter G, Steurer S, Clauditz TS, Krech T, Wittmer C, Lutz F, Lennartz M, Janssen T, Hakimi N, Simon R, et al. Clinical utility of quantitative Gleason grading in prostate biopsies and prostatectomy specimens. Eur Urol. 2016; 69(4):592-8.

17. Kononen J, Bubendorf L, Kallioniemi A, Barlund M, Schraml P, Leighton S, Torhorst J, Mihatsch MJ, Sauter G, Kallioniemi OP. Tissue microarrays for high-throughput molecular profiling of tumor specimens. Nat Med. 1998; 4(7):844-7.

18. Weischenfeldt J, Simon R, Feuerbach L, Schlangen K, Weichenhan D, Minner S, Wuttig D, Warnatz HJ, Stehr H, Rausch T, et al. Integrative genomic analyses reveal an androgen-driven somatic alteration landscape in earlyonset prostate cancer. Cancer Cell. 2013;23(2):159-70.

19. Minner S, Enodien M, Sirma H, Luebke AM, Krohn A, Mayer PS, Simon R, Tennstedt P, Muller J, Scholz L, et al. ERG status is unrelated to PSA recurrence in radically operated prostate cancer in the absence of antihormonal therapy. Clin Cancer Res. 2011;17(18):5878-88.

20. Weischenfeldt J, Simon R, Feuerbach L, Schlangen K, Weichenhan D, Minner $S$, Wuttig D, Warnatz HJ, Stehr H, Rausch T, et al. Integrative genomic analyses reveal androgen-driven somatic alteration landscape in early-onset prostate cancer. Cancer Cell. 2013;23(2):159-70.

21. Gao J, Aksoy BA, Dogrusoz U, Dresdner G, Gross B, Sumer SO, Sun Y, Jacobsen A, Sinha R, Larsson E, et al. Integrative analysis of complex cancer genomics and clinical profiles using the cBioPortal. Sci Signal. 2013;6(269):pl1.

22. Tomlins SA, Rhodes DR, Perner S, Dhanasekaran SM, Mehra R, Sun XW, Varambally S, Cao X, Tchinda J, Kuefer R, et al. Recurrent fusion of TMPRSS2 and ETS transcription factor genes in prostate cancer. Science. 2005; 310(5748):644-8.

23. Taylor BS, Schultz N, Hieronymus H, Gopalan A, Xiao Y, Carver BS, Arora VK, Kaushik P, Cerami E, Reva B, et al. Integrative genomic profiling of human prostate cancer. Cancer Cell. 2010;18(1):11-22.

24. Brase JC, Johannes M, Mannsperger H, Falth M, Metzger J, Kacprzyk LA, Andrasiuk T, Gade S, Meister M, Sirma H, et al. TMPRSS2-ERG -specific transcriptional modulation is associated with prostate cancer biomarkers and TGF-beta signaling. BMC Cancer. 2011;11:507.

25. Bawa P, Zackaria S, Verma M, Gupta S, Srivatsan R, Chaudhary B, Srinivasan S. Integrative analysis of Normal long intergenic non-coding RNAs in prostate Cancer. PLoS One. 2015;10(5):e0122143.

26. Villar V, Kocic J, Bugarski D, Jovcic G, Santibanez JF. SKIP is required for TGFbeta1-induced epithelial mesenchymal transition and migration in transformed keratinocytes. FEBS Lett. 2010;584(22):4586-92.

27. Burdelski C, Bujupi E, Tsourlakis MC, Hube-Magg C, Kluth M, Melling N, Lebok P, Minner S, Koop C, Graefen M, et al. Loss of SOX9 expression is associated with PSA recurrence in ERG-positive and PTEN deleted prostate cancers. PLoS One. 2015;10(6):e0128525.

28. Burdelski C, Menan D, Tsourlakis MC, Kluth M, Hube-Magg C, Melling N, Minner S, Koop C, Graefen M, Heinzer H, et al. The prognostic value of SUMO1/Sentrin specific peptidase 1 (SENP1) in prostate cancer is limited to ERG-fusion positive tumors lacking PTEN deletion. BMC Cancer. 2015;15:538.

29. Melling N, Rashed M, Schroeder C, Hube-Magg C, Kluth M, Lang D, Simon R, Moller-Koop C, Steurer S, Sauter G, et al. High-level gamma-Glutamylhydrolase (GGH) expression is linked to poor prognosis in ERG negative prostate Cancer. Int J Mol Sci. 2017;18(2):286. https://doi.org/10.3390/ ijms 18020286

30. Grupp K, Boumesli R, Tsourlakis MC, Koop C, Wilczak W, Adam M, Sauter G, Simon R, Izbicki JR, Graefen M, et al. The prognostic impact of high Nijmegen breakage syndrome (NBS1) gene expression in ERG-negative prostate cancers lacking PTEN deletion is driven by KPNA2 expression. Int J Cancer. 2014;135(6):1399-407.

31. Egevad L, Algaba F, Berney DM, Boccon-Gibod L, Comperat E, Evans AJ, Grobholz R, Kristiansen G, Langner C, Lockwood G, et al. Interactive digital slides with heat maps: a novel method to improve the reproducibility of Gleason grading. Virchows Arch. 2011;459(2):175-82.

Ready to submit your research? Choose BMC and benefit from:

- fast, convenient online submission

- thorough peer review by experienced researchers in your field

- rapid publication on acceptance

- support for research data, including large and complex data types

- gold Open Access which fosters wider collaboration and increased citations

- maximum visibility for your research: over $100 \mathrm{M}$ website views per year

At $\mathrm{BMC}$, research is always in progress.

Learn more biomedcentral.com/submission 